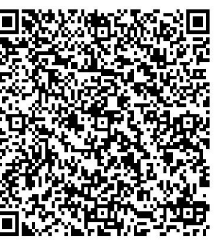

\title{
RESPONSIBLE TOURISM: A DESTINATION PERSPECTIVE
}

Vinodan. $A^{*}$

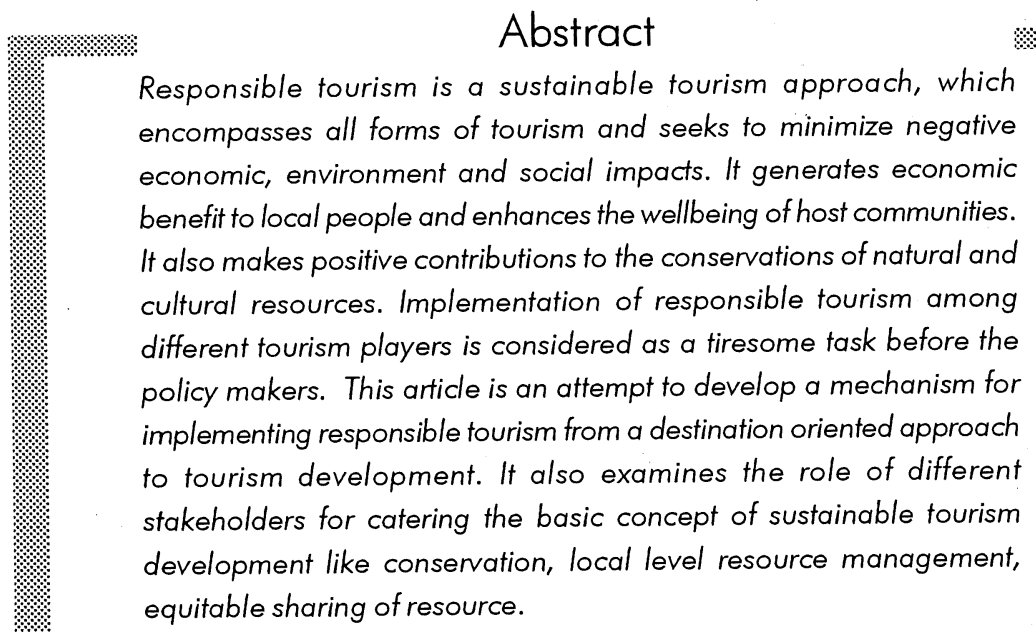

* Faculty, Indian Institute of Tourism and Travel Management, Bhubaneswar, Orissa, India. Email:vinodan.iittm@gmail.com 


\section{Introduction}

The term development and its sustainability is a widely debated topic these days. A consensus of these terms is considered as a very important area in the wake of policy decision and its implementation. Sustainable approach to development in all developmental areas is identified as a hurdle of processing the input for a desired outcome. As one of the largest growing as well as multi impacted industry in the world, tourism need special attention in this regard. As recognized by the economy tourism, forms a rising share in discretionary income and providing new opportunities for upgrading local environments. It has positive impact on economy, environment and society. The contribution to states balance of payment, on employment and gross income and production are getting prominence over other forms of industrial operations, which also acts as the main stimulator in regional development like infrastructural and marketing initiatives.

World Travel and Tourism Council undertakes extensive annual macro-economic research, which assesses the current and projected impact of Travel \& Tourism on a total of 174 national economies around the world. The latest research shows that the industry currently generates 234.3 million jobs or 8.7 per cent of total employment and contributes over 10.3 percent (both direct and indirect) of global GDP. The ten-year annualized growth (2007-2016) forecast is 4.2 per cent per annum illustrating the outlook for strong long-term growth.

Table 1: International Tourist Arrival

\begin{tabular}{|l|c|c|}
\hline Regional Market Share & $1995(\%)$ & $2006(\%)$ \\
\hline Europe & 58.6 & 54.5 \\
\hline Asia and the Pacific & 15.6 & 19.8 \\
\hline Americas & 19.8 & 16.1 \\
\hline Africa & 3.6 & 4.8 \\
\hline Middle East & 2.5 & 4.8 \\
\hline
\end{tabular}

Source: UNWTO World Tourism Barometer October 2007

Regionally, tourist movement is undergoing a substantial change. Based on the above statistics, Asia Pacific is expected to continue leading growth in international tourism. Africa and Middle East is gaining tourism in number of tourist as well as tourism receipts. In Asia, China and India are considered as the best selling 
destination in the world because of economic strength, proper promotional efforts and introduction of low cost carriers.

India has immense possibilities of growth in the tourism sector with vast cultural and natural attractions. Though India's contribution to world tourism is very low, around $0.52 \%$ of total arrival and $0.89 \%$ of foreign exchange, there has been a substantial change in the in flow of tourists to India. Foreign tourist arrivals to India 11.40 million in 2006 changed to $14.7 \%$ compared to last year, domestic tourist visits of 461.16 million in 2006 changed to $18.1 \%$. Employment generated under tourism sector is $8.78 \%$ of overall employment, that is 41.8 million. (Travel and Tourism Barometer October 2007)

\section{Literature Review}

There are a large number of discourses underway on environment, development, inclusive growth, conservation and livelihood, participatory management of resources etc., besides studies on negative and positive impacts of tourism and related projects. As a growing segment of the economy the impact of tourism on society, economy and environment were also recognized as research topics. In this direction Foster (1960) undertook a study on impact of tourism on society. Rivers (1973) Jafari (1974) Ghosal (1975) Doxey (1975) Britton (1977) Hope (1980) Cooke (1982) Cohen (1982) Mathieson and Wall (1982) Murphy (1985) Getz (1986) Davis, Allen and Cosenza (1988) Pearce (1989) Perdue and Allen (1990) Butler (1991) Evans (1993) Ryan and Montgomery (1994) Chattopadyay (1995) Hunter (1997) Khan (1997) Darmarajan (1999) Batta (2000), and Hughes and Saunders (2003), have all made important contributions on tourism impacts, community participation and equitable resource sharing. Apart from these theoretical contributions to the sustainable development of tourism there are numerous experimental initiatives that are underway. South African initiatives on responsible tourism, eco tourism initiatives in Nepal, Costa Rica, Belize, Canada, Kerala (India) etc were reviewed.

\section{Sustainable Tourism}

Sustainable and equitable development is the challenge of these days. The dynamics of the consumption-poverty-inequality-environment nexus are accelerating. Trends in this nexus continues without a change, i.e. shifting from polluting to cleaner goods and production technologies, promoting goods that empower poor producers, shifting priority from consumption for conspicuous display to meeting basic needs. The traditional developmental approaches failed to address this nexus. Consistent 
efforts like UN Conference on Human Environment in 1972, followed by the Brundtland Commission adopted a road for future development. As a major segment of the economy tourism's interaction with other types of resources were also discoursed.

The term sustainable tourism has initially been introduced in the context of environment. Gradually it enlarged its application as sustainable development tool by broadening of the spheres of influence of tourism. Manila Declaration on World Tourism (1980) calls for the protection, enhancement and improvement of various components of environment for the harmonious development of tourism. The principle of sustainable tourism was proposed as early as 1988 by the World Tourism Organization, with sustainable tourism being

"Envisaged as leading to the management of all resources in such a way that economic, social and aesthetic needs can be fulfilled while maintaining cultural integrity, essential ecological processes, and biological diversity and life support systems".

Action Strategy for Sustainable Tourism of Globe 90 Conference, Vancouver, Canada suggests sustainable tourism should have the following objectives;

To develop greater awareness and understanding of the significant contributions that tourism can make to environment and the economy;

To promote equity and development;

To improve the quality of life of the host community;

To provide a high quality of experience for the visitor; and

To maintain the quality of the environment on which the foregoing objectives depend.

One of the major comprehensive programmes of action in this direction is the Agenda 21 for Travel and Tourism Industry jointly initiated by Earth Council, World Travel and Tourism Council and World Tourism Organization. This document is of particular significance to all stakeholders of tourism development. Recently Swarbrooke (1999) has suggested a variation of the Brundtland Commission definition of sustainable development to sustainable tourism:

"Forms of tourism which meets the needs of tourists, the tourism industry, and host communities today without compromising the ability of future generations to meet their own needs" 
A comprehensive programme of action is inevitable to reach all corners of sustainability in tourism development. Integrated approach of assigning responsibility to all players can bring a positive result for a better future.

The tourism policy document of India 1982 and 2002 reiterated the need for sustainable development of tourism programmes as a catalyst in employment generation, environment regeneration, development of remote areas and development of women and other disadvantaged groups in the country. It also emphasized the need for conserving the invaluable cultural and natural heritage in tune with India's traditional philosophy of giving the highest honour to a guest 'Atithi Devo Bhava'.

Continued growth and growing economic importance of tourism in developing countries especially a country like India which is full-fledged with a variety of resources needs enhanced policies and planning to raise the sustainability in tourism and to increase the contribution of tourism to the overall sustainable development. Globally, national governments and international agencies are framing different programmes of action for sustainable tourism. The role of Panchayatraj institutions, local bodies, co-operatives, non-governmental organizations are very important for sustainable tourism programmes. Enterprising local youth to create tourism awareness and product development and in arranging tourist facilities including safety and security of tourist is the core of tourism development in a sustainable way.

\section{Responsible Tourism}

Tourism boom threatens to became self destructive if it continues to expand with out fetter. An integrated approach to tourism development is necessary, since tourism is integrally and structurally linked to the majority of the economic sectors. Thereby it could generate great economic and social benefits for the host communities, contributes to the development of rural areas and contributes to poverty's eradication in less developed areas, As natural and cultural attractions or thematic activities in these fields are key ingredients of a sustainable tourism product. Sustainable tourism promotes better understanding of the regions' cultural, social, economic and environmental issues; in this juncture the management of sustainable tourism requires active and balanced partnership between public, regional and local planning on one hand, and tourism business and all other stakeholders on the other hand; decentralisation of decision making power to local level is necessary to develop economic, social and environmental sustainable and responsible tourism. Responsible tourism strikes a balance between the needs of environment, the respect for the culture, and wish the people to live in a world without borders. Goodwin (2007) pointed that responsible tourism is triple bottom line approach, which cover 
- social, economical and environmental - aspects of tourism development by relishing the world's culture, habitat and species. It considers sustainability as a broad aspiration. Transparency is core in development objectives under responsible tourism. Different stakeholders can exercise the action under responsible tourism in different ways in different places.

Cape Town Declaration 2002 on Responsible Tourism in destination formulated framework for the sustainable development of tourism in a responsible way "to create better places for people to live in and for people to visit" by suggesting to:

- Minimize the negative economic, environmental and social and cultural impacts of tourism

- Generate greater economic benefits for local people and enhance the well being of host communities, by improving working conditions and access to industry

- Involve local people in decision making and resource sharing that effect their life and life chances

- Make positive contributions to the conservation of natural and cultural heritage embracing diversity

- Provide more enjoyable experience for tourist through more meaningful connections with local people, and greater understanding of local cultural, social and environmental issues

- Provide access for physically challenged people; and

- Build local pride and confidence through mutual respect

Besides this, Kerala Declaration (2008) on responsible tourism reiterates its commitment on destination based management practices by focusing on local economy, wellbeing, local culture and environment for equitable access and distribution of resources for a sustainable society.

\section{Discussion}

It is accepted that the sustainable development of tourism is the need of the hour for conservation, equity, and inclusive growth in different areas of destination development. However, a well-planned sustainable tourism programme can do a better job in uplifting the society. An examination of existing tourism management mechanisms in India were made in connection with this study. It has been observed 
that existing 'so called' sustainable tourism projects are managed by different stakeholders like government, NGO's, locally initiated development committees or other public private partnership. But the focus of the members of these institutional mechanisms is hardly benefiting out of tourism operations. Lack of coordination among different stakeholders is quite visible in ensuring sustainable outlook for developmental initiatives in destination areas. Another important lacuna with regard to tourism development is the absence of proper policy guidelines in formulating important programme of action and who should lead and coordinate all activities, which causes a lot of futile exercise in resource management. This is hampering their collective effort not only for promotion and marketing but also in conservation and livelihood issues. Such a myopic view of tourism will render destination development a futile operation. At this juncture, concept of responsible tourism is suggested by assigning different responsibilities to various stakeholders in tourism and its coordination. This article identifies different core areas of responsibility and how this responsibility can get it done through a destination point of view with a new destination management framework.

\section{Responsibility Areas}

Identifying the core responsible areas in tourism development in tune with sustainable development of the region is the key task before the policy makers. These could be able to use the natural, social and cultural resources in a sustainable manner by supporting local economic activities, involving local communities in decision making, reducing the over consumption and wastage and consultation with other stake holders including NGO's and educational institutions. Maintaining and promoting natural and socio cultural diversity in tourism development, need responsible approach. Following areas are identified as 'core responsible areas' as common modalities for developing tourism destination responsibly in the context of sustainable development.

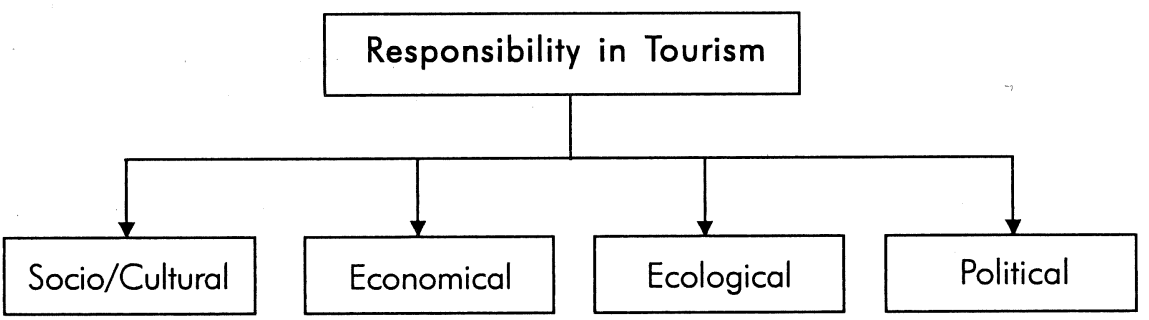




\section{Economic}

DAssessment of local economic impacts before developing tourism and exercise preference for those forms of development that benefit local communities and minimize negative impacts on local livelihoods

> Maximize local economic benefits by increasing linkages and reducing leakages, by ensuring that communities are involved in, and benefit from, tourism.

$>$ Develop quality products that reflect, complement, and enhance the destination brand image.

$>$ Market tourism in ways which reflect the natural, cultural and social integrity of the destination, and which encourage appropriate forms of tourism.

$>$ Adopt equitable business practices, pay and charge fair prices, and build partnerships in ways in which risk is minimized and shared, and recruit and employ staff from the destination area.

$>$ Provide appropriate and sufficient support to small, medium and micro enterprises to ensure tourism-related enterprises thrive and are sustainable.

$>$ Ensuring an integrated financing option for these enterprises can secure a confidence in destination development.

\section{Socio Cultural}

$>$ Actively involve the local community in planning and decision-making and provide capacity building to make this a reality.

$>$ Assess social impacts throughout the life cycle of the operation including the planning and design phases of projects and conduct social audit in order to minimize negative impacts and maximize positive ones.

$>$ Endeavor to make tourism an inclusive social experience and to ensure that there is access for all, in particular vulnerable and disadvantaged communities and individuals.

$>$ Combat the sexual exploitation of human beings, particularly the exploitation of children.

D Sensitize host community about the exploitation of various types and ensure protection of host culture, through maintaining and encouraging social and cultural diversity. 
$>$ Endeavor to ensure that tourism contributes to improvements in health and education.

\section{Environmental}

$>$ Introduce environment impact assessment throughout the life cycle of tourist establishments and operations - including the planning and design phase and ensure that negative impacts are reduced to the minimum and maximizing positive ones.

$>\quad$ Use resources sustainably, and reduce waste and over-consumption. Manage natural diversity sustainably, and where appropriate restore it; and consider the volume and type of tourism that the environment can support, and respect the integrity of vulnerable ecosystems and protected areas.

$>$ Promote education and awareness for sustainable development - for all stakeholders.

$>$ Raise the capacity of all stakeholders and ensure that best practice is followed, for this purpose consult with environmental and conservation experts.

\section{Political}

$>$ Assume the responsibilty of ressource management by mobilising opinion for all policy decisions.

$>$ Framework for policy formulation and coordination of activities concerned.

$>$ Mobilise all stake holders in decision making process through participation in meeting and implementation of the programmes.

$>$ Comply with all regulatory mechanism in destination and frame timely regulations and modalitites for equitable resource sharing for an inclussive growth.

\section{Destination Management Framework}

The concept of destination management has been changing very fast according to the changes in the economy system of a nation. Based on their political ideology the resource management practices always vary. It has been observed that private players are getting their momentum in these days for managing the country's resources. Tourism is not an exemption; private players manage many destinations 
in the world. In the context of Indian economic scenario the destination development is almost by private players even in state owned properties. Public private partnership is an innovative mode of resource management in tourism scenario in India and other developing countries. The study suggest for a locally initiated destination management framework keeping in mind the concept of public private partnership mode of development. Emerging concept of tourism developments like pro poor tourism, community based tourism; ecotourism etc. clearly argues for a collaborative form of destination development mechanism which call for a better approach to destination management with an environment of 'working together' for addressing the core developmental issues of regions through different tourism programmes.

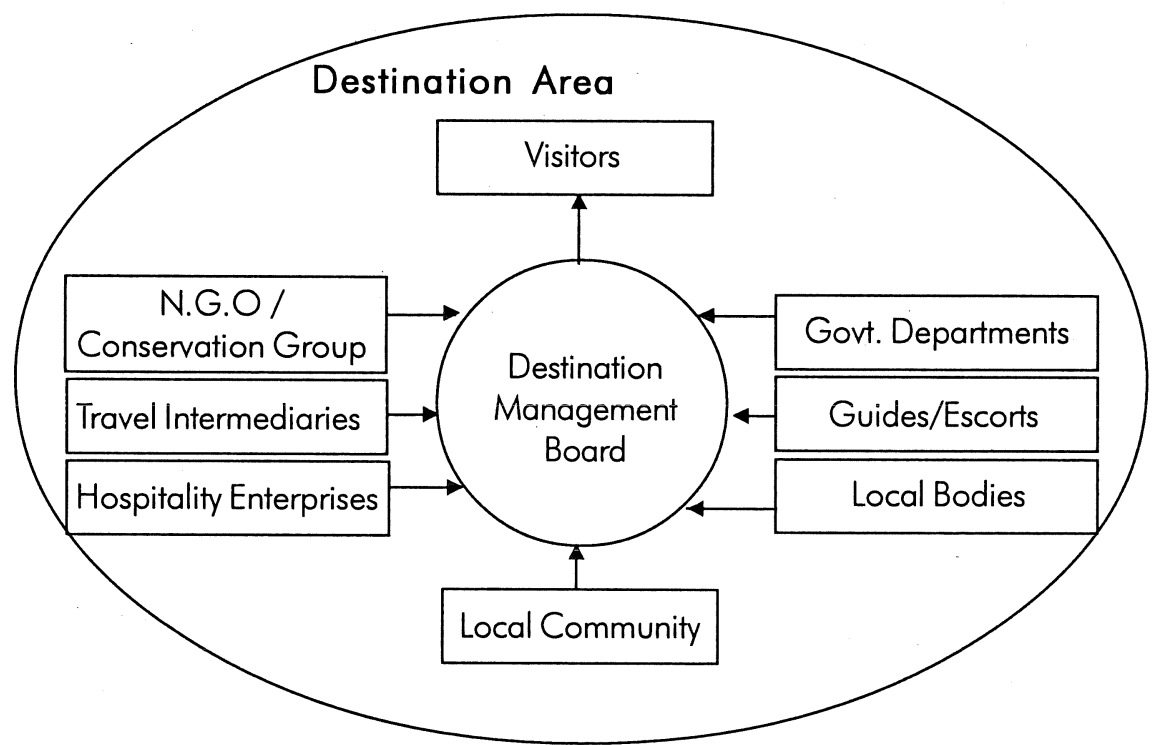

This frame work is for a sustainability management system by combining all stake holders in an area like travel intermediaries, hospitality enterprises, government departments, local bodies, guides and escorts and local community for measuring monitoring and reporting for a better control the negative impacts of activities thereby ensuring maximum satisfaction to visitors. Specific model of representation in the board is always destination specific since the sustainability varies place to place. It can be considered by giving fair representation to various stakeholders. While keeping the destination specific sustainability following activities are suggested under a destination management board.

- Regulation regarding visit to site according to the destination specifications

- Campaign for an all season tourism for reducing overflow in peak season 
- Control of pollution and seek for alternative energy option.

- Provision for research in traditional knowledge and conservation in cooperation with research institutions for decision-making process.

- Impact assessment related to eco system, biodiversity, and local indigenous culture.

- Certification for destination and other enterprises

- Consolidation of tourism community fund of various committees of local people involved in the destination management.

- Explore the potential for environmental accounting and social auditing and mobilize and disseminate sustainability report of each enterprise and publish consolidated report of the destination.

- Develop micro and small enterprises for all participating committees

- Act as nodal agency for micro credit option in association with banks and financial institutions.

- Liaison with state and central government agencies and media.

- Incentives for those enterprises who comply to all assumed responsibilities.

- Training for local people in updating changes.

- Information management.

- Human Resource inventory

- Feasibility study of different products.

- Creation and management of 'sustainability fund' mobilized from stakeholders,

- Arrange responsible tourism education among all stakeholders of tourism address conservation of resources and safety and health related issues of local people and provision for other social security measures.

\section{Stakeholders Responsibility}

Irrespective of approaches development is always meant for the people of a region. However, the attitude of people towards development is very important in fructifying the programme. A well informed society's contribution is always much valuable in 
all spheres of developmental process. Responsible approach to tourism development encompasses a set of principles, policy prescriptions and management methods which lead to tourism development in such a way the destination resources are protected, ensuring participation of all stake holders in policy formulation and implementation. Actions of all players in tourism are coordinated in tune with developmental needs of present population without impairing the ability of future tourism needs. Conceptualisation of role of stakeholders in the context of responsible tourism is a cumbersome task since sustainability parameters are destination specific. A model destination management framework would always seek for a common guideline applicable to majority of destination management programme, and at the same time it tries to heighten the role of key players especially institutional players like hospitality enterprises, travel agencies or tour operations, transport operators.

Hospitality enterprises include all types of catering, boarding and lodging amenities at the destination. Travel facilitators like travel agencies, tour operators, tour escorting and guiding firms and different transport undertakings. Following activities are suggested to each enterprise in a destination:

- Set responsible common goals

- Establish individual policies and programmes for responsible tourism

- In source local community to the organization and outsource institutional activities only to local people or their groups

- Expand charity portfolio of the institute for a sustainable surrounding

- Involve all staff members irrespective to their hierarchal order

- Information dissemination among organization motto and ensure their cooperation at all levels

- Inform suppliers of senvices regarding responsible practices and secure their cooperation

- Induce the suppliers and other partners to participate and introduce new methods for responsible tourism

- Practice environmental accounting, environmental audit and social audit in the organizational activities.

A traveler can play very important role for sustainable tourism in a responsible way. According to The International Ecotourism Society, one million responsible holidays 
were taken in 2006 and forecast growth of twenty five percent per year. In this model of destination management, the visitor is not part of destination management board, same time he has to cooperate with various activities, and thereby become part of destination management. In a destination he has to:

- Respect human rights

- Be tolerant and respect diversity

- Conserve natural environment

- Respect cultural resources

- Follow principles of fair trade

- Ensure health matters and provisions

- Learn customs, norms and traditions

- Familiarize local rules and regulations

Local community or community organizations of a destination is a focal point of all forms of tourism development of these days. The role of community towards tourism management is also widely discussed and experimented. The communites are always advised to understand taste and preferences of visitors and deliver services accordingly. They must be aware of value of their culture and indigenous practices and coordinate with tourism operations of the area as a product as such or as a value addition to the existing prime products. Awareness among them will help to use their products wisely and judiciously. Initiative for regeneration of resources both natural and cultural is very important in the context of responsible tourism.

Local non-governmental organizations working for conservation of resources can play a very active role in promoting sustainable destination management strategies. Advice from theses group gives a concrete result in maintaining sustainability. Thanal, a Kerala based NGO promoting zero waste in Kovalam, an international beach in India was widely acclaimed among tourism development scenario.

Local bodies of the respective region, government departments who administer resources of the destination including tourist attractions and the special tourism agencies like ministry of tourism, local tourist administrators are coordinated in destination management. Local law and order issues, logistics of resources and free movement of people are vested with local panchayat raj institutions. The government departments can be a part of destination management and regulate and monitor operations, and can also promote inter destination tourist attractions. 


\section{Conclusion}

For a sustainable tourism development we need to ensure participation of all on a common platform. Absence of such a common platforms leads to inequitable resource sharing and thereby it hamper the basics of sustainable development. As stated earlier sustainability and stakeholders are always destination specific so a straight way framework under destination management would be very difficult, so modifications are always suggested.

The destination management board constituted in this study is only to minimize leakages and promote linkages. Centralized information management at destination level promotes cohesion among various parties. Unless the responsibilities are properly communicated and coordinated the effort for sustainable tourism development would become a futile exercise.

\section{References}

- Batta, (2000), Tourism and the Quest for Sustainability, Indus, New Delhi.

- Britton, R.A (1977) 'Making Tourism More Supportive of small- state development: the case of St. Vincent' Annals of Tourism Research 4(5).

- Butler, R.W (1991) 'Tourism, environment, and sustainable development' Environmental Conservation 18(3).

- CESD/TIES working paper No. 104, 2005.

- Chattopadyay, (1995), Economic Impact of Tourism', Kanishka, NewDelhi.

- Cohen.E (1982), "A Marginal Paradise: Bungalow Tourism on the Islands of Southern Thailand," Annals of Tourism Research. 9(2).

- Cooke,K. (1982),"Guidelines for Socially Appropriate Tourism Development in British Columbia", Journal of Travel Research 21(1).

- Darmarajan S (1999), "Tourism an Instrument for Development". Yojana, August.

- Davis, Allen and Cosenza (1988), "Segmenting Local Residents by Their Attitude, Interest and Opinions Towards Tourism". Journal of Travel Research 27(2).

- Doxey, GV. (1975) 'A causation theory of visitor- resident irritant: methodology and research interference' TTRA conference paper California pp195-198.

- Foster.J (1964), "The Sociological Consequence of Tourism" International Journal of Comparative Sociology. Vol; V.

- Getz (1983) “Capacity to Absorb Tourism: Concepts and Implications for Strategic Planning, Annals of Tourism Research, 10(2).

- Ghosal (1975), A "Cost - Benefit Study of Tourism", NACER, XI, New Delhi. 
- Goodwin H (2007) Work shop on Responsible Tourism Trivandrum Kerala February $3 \& 4$.

- Hope, KR. (1980) 'The Caribbean tourism sector: recent performance and trends' Tourism Management $1(3)$

- Hunter, C. (1997) 'Sustainable Tourism An Adaptive Paradigm', Annals of Tourism Research 24(4).

- Jafari. J (1974), "The Socio Economic Cost of Tourism Development" Annals of Tourism Research 1 (7).

- Khan, M.M (1997)' Tourism development and Dependency Theory: Mass tourism vs. Eco tourism' Annals of Tourism Research 24(4).

- Krippendorf, J (1987) The Holiday Maker, Understanding the Impact of Leisure and Travel, Heinemann, London.

- Mathieson, A. and Wall, G (1982) Tourism: Economic, Physical and Social Impacts, London. Logman.

- Murphy, PE. (1985), Tourism - a Community Approach, Routledge, London.

- Pearce, (1989), Tourism Development Longman, London.

- Rivers. P (1973) Tourist Troubles, New Society.

- Ryan, C and D.Montgomery, (1994), "The Attitude of Bakewell Residents to Tourism and Numbers in Community Responsive Tourism," Tourism Management (14).

- www.icrtindia.org/kd.htm

- www.icrtourism.org/assets/pdf 